\title{
Application of Compact Type Composite Cross arm in Tower Design
}

\author{
Haowei PEI, Liang ZHANG, Chen CHEN, Qingfeng ZHANG, Fei ZHOU, Kai NIU \\ State Grid Henan Economic Research Institute \\ Henan, China. \\ e-mail: 296708793@qq.com,550599894@qq.com, 56990512@qq.com,1084606835@qq.com,137037770223@163.com, \\ $365415011 @ q q . c o m$
}

\begin{abstract}
This paper discussed the structure composition and connection mode of composite cross arm, By tightened the vibration, redesigned the tower head structure of cup-tower, cathead tower and Upper Shape Tower using composite cross arm, the corridor width decreased by $3.2 \mathrm{~m}$ and $3 \mathrm{~m}-3.6 \mathrm{~m}$, Effectively solved the problem of the increasing of the corridor width when the Composite Cross arm was applied the conventional tower head. The 3 towers of technical and economic comparison, results showed that the Compact type composite cross arm upper shape can obtain the minimum line width of corridor, compact composite cross arm cup-tower has the best technology and economy.
\end{abstract}

Keywords-composite cross arm; tower design; structure type; design principle

\section{INTRODUCTION}

At present, China's overhead transmission lines are mostly made of steel structure. With the continuous upgrading of the power grid system, the transmission lines go to EHV, high capacity, compact type and multi-loop. Due to the conductivity of the steel itself, the width of the corridor increases, resulting in reduced economic efficiency of the steel structure, at the same time, the increase in demand for steel will also consume more non-renewable energy, resulting in ecological damage. The use of appropriate new environmentally friendly high-performance materials to replace steel will effectively alleviate the above contradictions.

Fiber reinforced resin-based composite material has excellent electrical insulation, light and high strength, corrosion resistance, performance can be designed and other characteristics, used in transmission tower structure can greatly reduce the tower size and corridor width, and improve the safe operation level of the line. At the same time, composite components are light and difficult to be stolen, greatly reducing the cost of transport installation and line maintenance. The application of composite materials to transmission towers has been studied by more and more domestic and foreign scholars.

As early as 1960s, Japan carried out the study of FRP material used in the transmission line cross load, and solved the flashover accident caused by windage very well ${ }^{[1]}$. The composite towers developed by America's Sharkspeare company worked in the high salt spray corrosion and often experienced hurricane Hawaii island for more than 40 years, and still continue to work, Strongwell, Newmark, Ebert and other FRP material manufacturers have also developed their own FRP transmission tower products, and has been a wide range of applications ${ }^{[2-6]}$. State Grid Wuhan Institute of high pressure in 2007 successfully developed a $10 \mathrm{kV}$ line lightning protection and pollution of the insulation tower head and cross ${ }^{[6,7]}$. Northwest Electric Power Design Institute and Xi'an Jiaotong University, through the experimental test and theoretical research, successfully developed a lattice composite tower, and in $\pm 660 \mathrm{kV}$ Yinchuan East converter station grounding line project pilot applied ${ }^{[8]}$. Jiangsu Shenma Electric Power Co., Ltd. developed a composite insulation cross, in December 2009 in Lianyungang $220 \mathrm{kV}$ Maoqiang line put into trial operation, the current performance indicators runs well ${ }^{[1]}$.

In this paper, the structural composition and connection mode, the tower structure type and the design principle of composite cross arm are studied, which provides reference for practical engineering applications.

\section{Structure And Connection Of Composite CROSS ARM}

For a space trussed tower, the composite cross arm is generally composed of a cross arm member subjected only by axial tension and a crossed member of bending moment and pressure. The pultruded profile has excellent axial characteristics, which can meet the stress characteristics of the bracelet members. The glass fiber winding structure has high reliability in both circumferential and axial directions, which can meet the compressive pressure of the crossBending requirements. Therefore, in this paper the cross arm wind component by pultrusion process, crossarm bottom member winding process pipe.

The perforation of the composite material is easy to cause damage to the internal fiber structure, weaken its overall strength and cause stress concentration, so it is not suitable for bolting.

In this paper, composite crossbar pipe fittings using casing glue and bolt piercing mixed connection. The advantages of bonding are as follows: stress concentration caused by no drilling, high connection efficiency, light structure, anti-fatigue, sealing, shock absorption and insulation performance; can effectively avoid the crack caused by drilling expansion, broken safety is good. The bolt connection is widely used in larger and important force bearing components. The advantage of the bolt connection is that it can be repeatedly assembled and disassembled in manufacture, replacement and maintenance. It is convenient 
for quality check and reliability of joints. The combination of these two methods, between the metal parts and composite by adhesive, between metal parts and metal parts connected by bolts, can give full play to the advantages of each connection, ensure the overall structure is safe and reliable, and simple management, conducive to mass production. Composite cross in the cable components, mainly to withstand the tension, the end of the connection process for the current technology mature crimping process.

\section{TOWER STRUCTURE TyPE}

At present, the composite cross arm in the cup tower or tower in the cathead tower less practical application, especially in mountain engineering is almost no application, The reason is that the cup tower or cathead tower cross arm less side, With composite cross arm, the width of the corridor will not decrease, but increase. There is no advantage for the corridor limited mountain project, so it is necessary to innovate the structure form for the use of composite material in the transmission line project, so as to give full play to the advantages of composite materials.

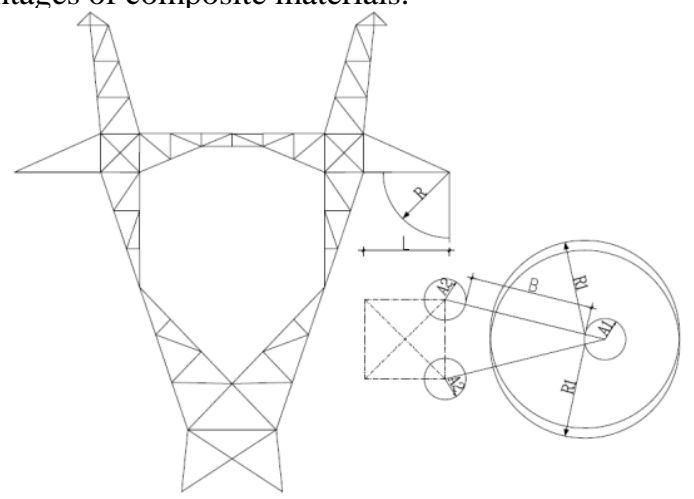

Figure 1. Conventional cup tower septal surface+ each gap's dimension of composite material crossarm.

\section{A. Tower Head Gap and Compact Type Arrangement}

According to the requirements of the electrical gap of tower head, if directly in the conventional cup tower head replacement composite crossarm, tower head related dimensions and gap were shown in Table 1, the specific dimensions are shown in Fig. 1, where A1 is the length of the metal part at the end of the crossarm and $\mathrm{A} 2$ is the length of the metal part at the root of the crossarm.

TABLE I. TOWERHEAD SIZE UNIT: M

\begin{tabular}{ccccccc}
\hline Tower type & R & R1 & B & A1 & A2 & L1 \\
\hline $\begin{array}{c}\text { Conventional cup tower septal } \\
\text { surface }\end{array}$ & & & & & & \\
$\begin{array}{c}\text { plus composite material } \\
\text { crossarm }\end{array}$ & 3.0 & 3.2 & 3.48 & 1.8 & 0.5 & 5.8 \\
\hline
\end{tabular}

It can be seen from Fig. 1 that the tower head size of the composite cross arm must meet three control conditions to meet the requirements of electrical use, which are facade gap $\mathrm{R}$, minimum insulation length $\mathrm{B}$ of composite and crossarm at the end of the metal component lightning clearance R. As a result, the width of the line corridor is increased by 1 meters when instead of the composite cross arm on the conventional cup tower head, which limits the application of the composite cross arm in the mountain engineering. So, it is recommended to use compact type composite material crossbar design, as shown in Figure 2.

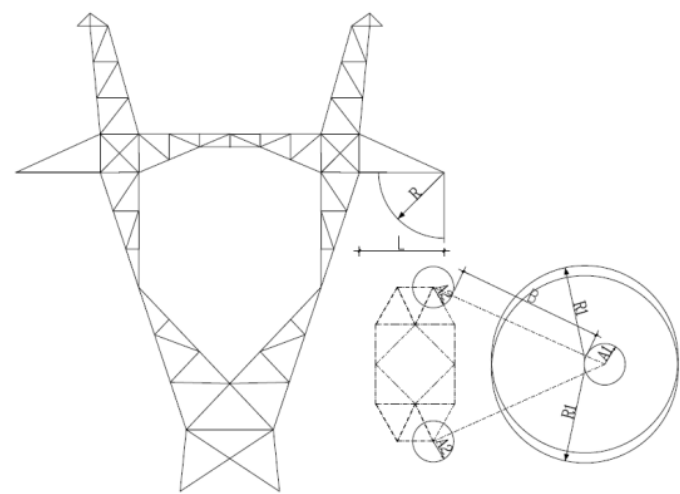

Figure 2. The compact type cup tower septal surface+ each gap's dimension of composite material crossarm

From Figure 2, by compact type septal surface design, the corridor width is $3.2 \mathrm{~m}$ less than the conventional cup tower, $4.2 \mathrm{~m}$ less than the conventional cup tower plus composite material crossarm, it solved the problem that the corridor becomes wider when the composite cross arm scheme is adopted.

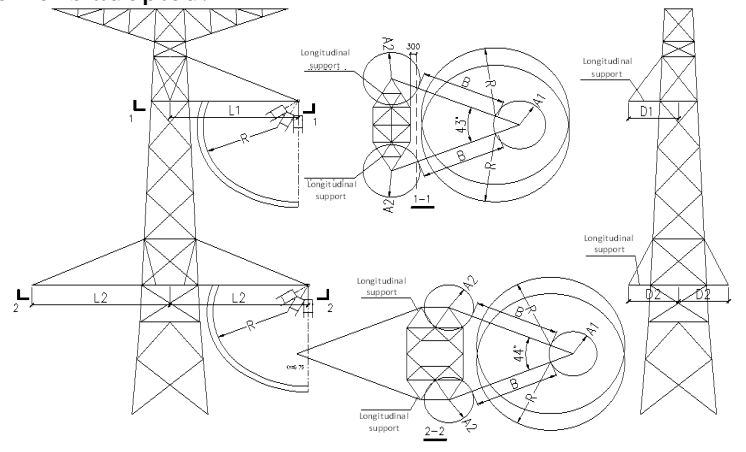

Figure 3. The compact type septal surface of upper shape tower + composite material crossarm.

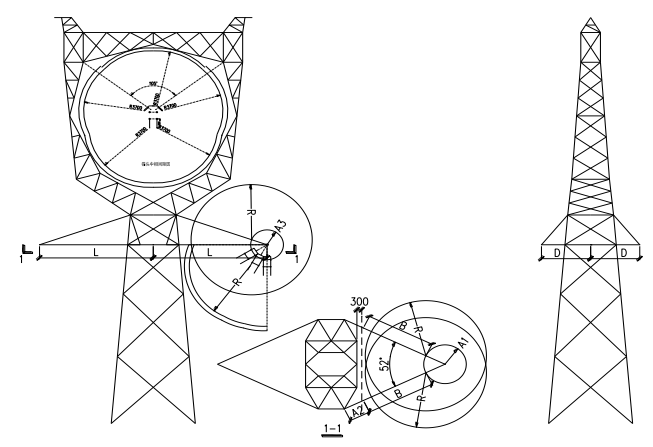

Figure 4. The compact type septal surface of cathead tower plus composite material crossarm. 
According to this design idea, the upper shape tower and the cathead tower were compared and analyzed, respectively as shown in Figure 3 and Figure 4.

In the same way as the cup tower, by setting the longitudinal brackets on the upper shape tower and the cathead tower, under the premise of meeting the minimum insulation length $\mathrm{B}$ of composite material, the composite crossarm section can be contracted to about $1.5 \mathrm{~m} \sim 1.8 \mathrm{~m}$ to the center of the line, so that the corridor of the line can be reduced by about 3 to $3.6 \mathrm{~m}$.

\section{B. Technical and Economic Comparison of Composite Cross Arm}

The above four types of tower dimensions are shown in the following figure.

As can be seen from the above table, the use of "the compact type upper shape tower of composite material crossarm" can get the smallest line corridor width.

As the wire is arranged in a triangular arrangement, the tower height of the "the compact type upper shape tower of composite material crossarm" and the "the compact type cathead tower of composite material crossarm" are about $6.5 \mathrm{~m} \sim 8.5 \mathrm{~m}$ higher than the conventional glass tower.

Under $20 \mathrm{~mm}$ ice area weather conditions, through the calculation of the tower and foundation in the depth of the construction drawings, the above three kinds of tower material specifications as shown in the table below. The foundation form was tentatively designed to dig the foundation.

Through the above analysis can be drawn, from the cost point of view, "the compact type upper shape tower of composite material crossarm" and "the compact type cathead tower of composite material crossarm" scheme although the corridor is small, but the body of large quantity and high cost, is not recommended. But the tower height and corridor width of the compact type cup tower of composite material crossarm are greatly improved compared with the conventional cup tower, and the cost is little different. It is suggested to adopt the compact type cup tower of composite material crossarm scheme.

TABLE II. SingLE LiNE Size COMPARISON TABLE

\begin{tabular}{|c|c|c|c|c|c|}
\hline \multirow[b]{2}{*}{ design scheme } & \multirow{2}{*}{$\begin{array}{c}\text { reference } \\
\text { practical } \\
\text { height }(m)\end{array}$} & \multirow{2}{*}{$\begin{array}{c}\text { Tower } \\
\operatorname{height}(\mathbf{m})\end{array}$} & \multirow[b]{2}{*}{$\operatorname{Root}$ open $(\mathbf{m m})$} & \multicolumn{2}{|c|}{ Line corridor } \\
\hline & & & & Corridor width(m) & $\operatorname{Comparison}(\mathbf{m})$ \\
\hline Conventional cup tower( $20 \mathrm{~mm}$ ice area) & 36 & 42 & 9000 & 21.0 & \pm 0 \\
\hline $\begin{array}{l}\text { the compact type upper shape tower of } \\
\text { composite material crossarm }\end{array}$ & 33 & 50.5 & 9560 & 15.1 & -5.9 \\
\hline $\begin{array}{c}\text { the compact type cathead tower of } \\
\text { composite material crossarm }\end{array}$ & 33 & 48.5 & 9400 & 15.2 & -5.8 \\
\hline $\begin{array}{l}\text { the compact type cup tower of composite } \\
\text { material crossarm }\end{array}$ & 33 & 39.2 & 8600 & 17.8 & -3.2 \\
\hline
\end{tabular}

TABLE III. TYPICAL TOWER INDEX COMPARISON TABLE

\begin{tabular}{|c|c|c|c|c|c|c|c|}
\hline \multirow{2}{*}{ design scheme } & \multirow{2}{*}{$\begin{array}{l}\text { Weight of single } \\
\text { tower composites } \\
\text { material }(\mathbf{k g})\end{array}$} & \multicolumn{2}{|r|}{ Tower } & \multicolumn{2}{|c|}{ Foundation beton } & \multicolumn{2}{|c|}{$\begin{array}{l}\text { Comparison of cost of single tower } \\
\text { (including tower material, composite } \\
\text { crossarm, foundation and insulator) }\end{array}$} \\
\hline & & $\begin{array}{l}\text { weight } \\
\text { (Ton) }\end{array}$ & proportion( $(\%)$ & $\begin{array}{l}\text { Single tower } \\
\text { beton }(\mathrm{m} 3)\end{array}$ & $\begin{array}{c}\text { proportion } \\
(\%)\end{array}$ & $\begin{array}{l}\text { material fee(Ten } \\
\text { thousand yuan) }\end{array}$ & proportion( $\%$ ) \\
\hline $\begin{array}{c}\text { Conventional cup } \\
\text { tower(20mm ice area) }\end{array}$ & 0 & 14.15 & $100 \%$ & 29.2 & $100 \%$ & 17.96 & $100 \%$ \\
\hline $\begin{array}{l}\text { the compact type upper } \\
\text { shape tower of } \\
\text { composite material } \\
\text { crossarm }\end{array}$ & 0.72 & 14.84 & $104 \%$ & 27.6 & $95 \%$ & 20.81 & $116 \%$ \\
\hline $\begin{array}{l}\text { the compact type } \\
\text { cathead tower of } \\
\text { composite material } \\
\text { crossarm }\end{array}$ & 0.52 & 15.56 & $110 \%$ & 31.6 & $108 \%$ & 21.67 & $120 \%$ \\
\hline $\begin{array}{l}\text { the compact type cup } \\
\text { tower of composite } \\
\text { material crossarm }\end{array}$ & 0.43 & 13.06 & $92 \%$ & 26.3 & $90 \%$ & 18.10 & $101 \%$ \\
\hline
\end{tabular}




\section{CONCLUSION}

(1) In this paper, the cross arm top chord component adopt pultrusion process, crossarm bottom chord component adopt winding process pipe. And the pipe component of composite cross arm is made up of sleeve rubber joint and bolt perforation. It can give full play to the advantages of each connection mode, ensure the safety and reliability of the overall structure, and easy to handle, and is conducive to mass production.

(2) The width of the corridor of the cup tower, the upper shape tower and the cathead tower was reduced by $3.2 \mathrm{~m}$ and $3 \mathrm{~m}-3.6 \mathrm{~m}$ respectively, which effectively solved the problem of increasing the width of the corridor when the conventional tower was applied.Through technical and economic comparison, the width of the three kinds of tower corridors is reduced by $5.9 \mathrm{~m}, 5.8 \mathrm{~m}$ and $3.2 \mathrm{~m}$ respectively, and the cost ratio is $116 \%, 120 \%$ and $101 \%$ respectively, compared with the conventional cup towers. Considering comprehensively, it was considered that the technology and economy of the compact type cup tower of composite material crossarm were the best.

\section{REFERENCES}

[1] Yang Min-xiang, Chen Yuan, Li Wei-guo. Research Progress on Composite Tower and Pole and its Key Technical Problems[J]. North China Electric Power, 2010(10):48-50.

[2] Wu Qing-hua,Wu Hai-yang. Research on Application of FRP to Electrode Line Project[J]. Electric Power Survey \& Design, 2010(12):60-64.

[3] Deng Shicong, Liu Ting, LI Hanming, etc. The Material, Electrical and Mechanical Characteristics Tests of Composite Poles for $110 \mathrm{kV}$ Overhead Transmission Lines [J]. Southern Power System Technology, 2011(3):36-40.

[4] HU Yi, Liu Ting. Experimental Research on Performance of Composite Materials Pole of $110 \mathrm{kV}$ Transmission Line[J]. High Voltage Engineering. 2011, 37[4]:801-807.

[5] FANG Donghong, HAN Jianping, CAO Cuiling .Advance In Application Of Composite Poles For Power Transmission[J]. Fiber Glass, 2008(6):31-39.

[6] Hu Yi, Wang Li-nong.Insulated Tower Top and Cross Arm to Prevent Lightning and Pollution Flashover[J]. High Voltage Engineering, 2007,33(12):108-110. 